\title{
Preparation and Characterization of Chitosan/Agar Blended Films: Part 1. Chemical Structure and Morphology
}

\author{
ESAM. A. EL-HEFIAN ${ }^{1 *}$, MOHAMED MAHMOUD NASEF ${ }^{2}$, and ABDUL HAMID \\ YAHAYA $^{3}$
}

${ }^{1}$ Chemistry department, Faculty of science, Azzawia University, Azzawia, Libya

${ }^{2}$ Chemical Engineering Department, Faculty of Chemical and Natural Resources

Engineering, Universiti Teknologi Malaysia, 81310 UTM Skudai, Johor, Malaysia

${ }^{3}$ Department of Chemistry, Faculty of Science, University of Malaya, 50603 Kuala Lumpur, Malaysia

eelhefian@yahoo.com

Received 13 July 2011; Accepted 27 August 2011

\begin{abstract}
Chitosan/agar (CS/AG) films were prepared by blending different proportions of chitosan and agar (considering chitosan as the main component) in solution forms. The chemical structure and the morphology of the obtained blended films were investigated using Fourier transform infrared (FTIR) and field emission scanning electron microscope (FESEM). It was revealed that chitosan and agar form a highly compatible blend and their films displayed homogenous and smooth surface properties compared to the individual pure components.
\end{abstract}

Key words: Chitosan, Agar, blended films, FTIR, FESEM.

\section{Introduction}

Polysaccharides are a class of natural polymers that have been receiving an increasing attention in various fields of industrial interest including food technology, pharmaceutics and waste water treatment ${ }^{1}$. This is because polysaccharides are renewable resources, abundant, nontoxic, inexpensive and biodegradable materials, in addition to their great potential to replace synthetic polymers in many applications ${ }^{2}$. Among polysaccharides, chitosan [poly (1,4- $\beta$-D-glucopyranosamine)], which is usually obtained by alkaline deacetylation of the second most abundant naturally occurring polymer i.e., chitin, possesses valuable properties (biocompatible, biodegradable, antibacterial nature and film forming ability) promoting its use in a variety of interesting applications ${ }^{3,4}$. Furthermore, chitosan has reactive amine side groups, which offer possibilities of modifications, graft reactions and ionic interactions ${ }^{5}$. Therefore, pure and modified chitosan have been evaluated for numerous applications, including medicine, food, cosmetics and wastewater treatment in various occasions ${ }^{6-10}$. Among all modification methods, blending of chitosan with other 
natural polymers has been proposed as a convenient and effective means to improve its physical properties to meet the requirements for practical applications. Studies on blend films of chitosan/cellulose ${ }^{11,12}$, chitosan/starch ${ }^{13}$, chitosan/gelatin ${ }^{14}$ and chitosan/collagen ${ }^{15}$ have been reported in various occasions.

Agar, an unbranched polysaccharide, is a hydrophilic colloid extracted from the family of seaweeds (Rhodophycae) having the structure of 1,4-linked-3,6-anhydro- $\alpha$-Lgalactopyranose ${ }^{16}$. One of the most important properties of agar is its ability to form reversible gels even at low concentration simply by cooling its hot aqueous solutions. This is due to the formation of hydrogen bonds ${ }^{17-19}$. This has given agar a wide use in a variety of industries including food industry products such as processed cheese, ice cream, bread and soft candy ${ }^{20,21}$. Blending agar with other polymers is very scarce. Hydrogel blends of agar with polymers such as poly (vinyl pyrrolidone) (PVP) have been prepared ${ }^{22}$. However and up to knowledge of the authors reports on blends of chitosan with agar have not been reported in literature.

Since, chitosan is known for film forming ability caused by rigidity imparted by the presence of hydrogen bonding in its structure, blending it with agar would help to improve its gelation and swelling properties while imparting mechanical strength to the agar. The similarity in the primary structures between agar and chitosan shown in Figure 1 suggests a high possibility for formation of a much needed homogeneous blend hydrogel films. The combination of the properties of chitosan including its antibacterial and biocompatibility with gel-forming agar makes the obtained hydrogel blend appealing for some biomedical applications.

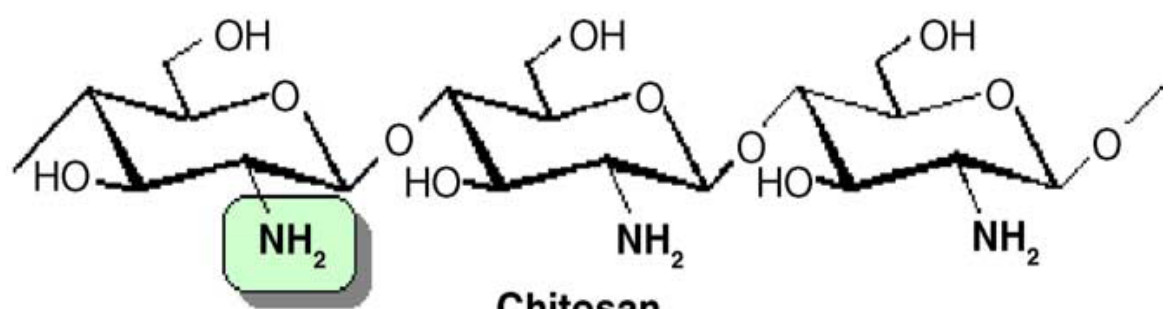

Chitosan

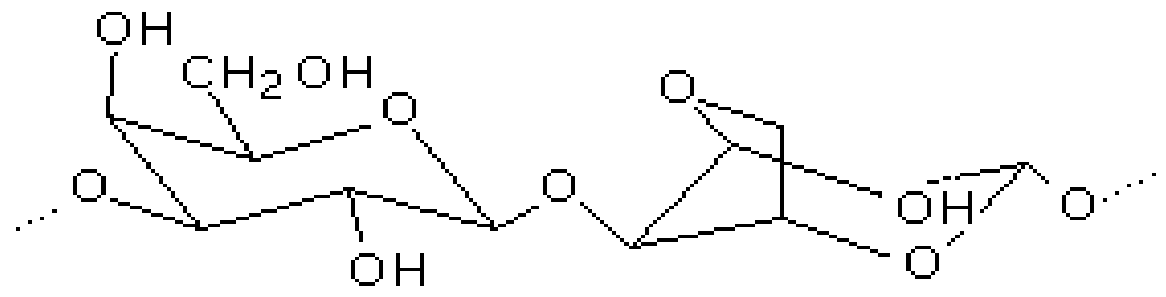

Agar

Figure 1: Chemical structure of chitosan and agar.

In this study, we report on preparation of chitosan/agar films obtained by physical solution blending of chitosan and agar at different proportions. FTIR spectral analysis was used to confirm the presence of functional groups of both chitosan and agar in the blend. Morphology of various blended films of chitosan/agar was investigated in correlation with the agar content in the blended films. The effect of the agar content on the thickness of the blend was also studied in this work. 


\section{Experimental}

\section{Materials}

Chitosan with a degree of deacetylation (DD) of $88.1 \%$ determined by UV method ${ }^{23}$ was obtained from a commercial source. Agar was purchased from Sigma-Aldrich and its molecular weight was $1.3 \times 10^{4} \mathrm{~g} \mathrm{~mol}^{-1}$. Acetic acid (glacial $100 \%$, pro-analysi) was purchased from Merck (Darmstadt, Germany). Ultra pure water (Maxima Ultra Pure Water, Elga-Prima Corp, UK) with a resistivity greater than $18 \mathrm{M} \Omega / \mathrm{cm}$ was used to prepare all solutions. All chemicals were used without further purification and freshly prepared solutions were used in all experiments.

\section{Preparation of solutions}

Chitosan was dried in an oven until a constant weight was observed. A $10 \mathrm{~g} \mathrm{~L}^{-1}$ solution of chitosan was prepared by dissolving $5 \mathrm{~g}$ of chitosan in $500 \mathrm{~mL}$ acetic acid $(0.1 \mathrm{M})$ followed by stirring and heating at $60^{\circ} \mathrm{C}$ for $16 \mathrm{~h}$. The solution was filtered to remove dust and other traces of impurities. Air bubbles formed in the solution were eliminated by keeping the solutions at room temperature for $2 \mathrm{~h}$. A similar $10 \mathrm{~g} \mathrm{~L}^{-1}$ solution of agar was prepared by dissolving $5 \mathrm{~g}$ in $500 \mathrm{~mL}$ preheated ultrapure water. The solution was then stirred and kept at about $75^{\circ} \mathrm{C}$ for $3 \mathrm{~h}$.

\section{Preparation of blend films}

The preparation of blend films of chitosan and agar was carried out at various proportions. The aqueous agar solution was added drop by drop to the chitosan solution, under continuous stirring at $90^{\circ} \mathrm{C}$ in various proportions by volume. The range of the added agar to chitosan solution was from $0-50 \mathrm{vol} \%$. Stirring was allowed to continue for 30 minutes after mixing. Films of the resulting homogeneous solutions were obtained by casting prescribed amounts of the blend solution onto polystyrene Petri dishes followed by drying at $60^{\circ} \mathrm{C}$ for $48 \mathrm{~h}$. The films were peeled off and kept under evacuated desiccator over a fresh silica gel until use. All films obtained were transparent and free of air bubbles.

Similar films from pure chitosan and agar were prepared using the same casting procedure and used as references.

\section{Film thickness}

The film thickness was measured with a digital micrometer (Mitutoyo, Japan) with $0.001 \mathrm{~mm}$ resolution. Several thickness measurements were taken at various positions on each specimen and the average values were recorded.

\section{Molecular weight measurements}

The molecular weight of chitosan was determined by gel permeation chromatography (GPC) equipped with a Waters 1515 HPLC pump and a Waters 2414 refractive index detector. The column used was PL aquagel-OH $30(8 \mu \mathrm{m}, 300 \times 7.5 \mathrm{~mm})$ and the solvent was $1 \%$ acetic acid solution. 


\section{FTIR measurements}

FTIR measurements of blend films $(10 \mu \mathrm{m} \pm 2$ thick) were performed on a Perkin Elmer (model-2000) spectrometer. The spectra were obtained at a frequency range of 4000-400 $\mathrm{cm}^{-1}$ with a resolution of $4 \mathrm{~cm}^{-1}$ and 8 -times scanning rate.

\section{FESEM measurements}

Surface morphology was investigated by a FEI Quanta 200F field emission scanning electron microscope (FESEM) (FEI, USA) controlled by a 32 bit computer system using Microsoft Windows 2000 as an operating system.

\section{Results and Discussion}

\section{Molecular weight of chitosan}

The molecular weight of chitosan used in this work was obtained by GPC and found to be $5.5 \times 10^{5} \mathrm{~g} \mathrm{~mol}^{-1}$. This value was found to be going along with some values reported in the literature. For example, Ladet et al. ${ }^{24}$ and Notin et al. ${ }^{25}$ reported values of $\mathrm{M}_{\mathrm{w}}$ of $5.5 \times 10^{5} \mathrm{~g}$ $\mathrm{mol}^{-1}$ and $5.4 \times 10^{5} \mathrm{~g} \mathrm{~mol}^{-1}$ respectively for chitosans with higher DD. Also Li et al ${ }^{26}$ reported a value of $\mathrm{M}_{\mathrm{w}}$ around $3.0 \times 10^{5} \mathrm{~g} \mathrm{~mol}^{-1}$ determined by GPC method for chitosan with $85 \%$ DD.

\section{Chemical structure}

Figure 2 shows a typical spectrum of pure chitosan film. The broad band at $3367 \mathrm{~cm}^{-1}$ is due to the $\mathrm{OH}$ stretching. The band at $1560 \mathrm{~cm}^{-1}$ is assigned for the $\mathrm{NH}$ bending (amide II) $\left(\mathrm{NH}_{2}\right)$ while the small peak at $1648 \mathrm{~cm}^{-1}$ is attributed to the $\mathrm{C}=\mathrm{O}$ stretching (amide I) $\mathrm{O}=\mathrm{C}$ NHR. The bands at 2927, 2884, 1411, 1321 and $1260 \mathrm{~cm}^{-1}$ are assigned to $\mathrm{CH}_{2}$ bending due to pyranose ring ${ }^{27}$. The band at $1380 \mathrm{~cm}^{-1}$ is due to $\mathrm{CH}_{3}$ wagging. The characteristic features of chitosan spectrum in this study are going along with previous reports ${ }^{28,29,13}$.

FTIR spectrum of agar film is presented in Figure 3. The absorption band at about 3400 $\mathrm{cm}^{-1}$ is associated with $\mathrm{O}-\mathrm{H}$ stretching ${ }^{30}$ while the peak at $2900 \mathrm{~cm}^{-1}$ is attributed to methoxyl groups ${ }^{31}$. The band at around $1643 \mathrm{~cm}^{-1}$ is due to the stretching vibration of the conjugated peptide bond formed by amine $(\mathrm{NH})$ and acetone $(\mathrm{CO})$ groups ${ }^{32}$. The peak at $1370 \mathrm{~cm}^{-1}$ is assigned to ester sulfate ${ }^{31}$ (not shown in general chemical structure in Figure 1 and their presence can be due to variation agar species and method of extraction) and the bands at 1070 and $930 \mathrm{~cm}^{-1}$ are associated with the 3,6-anhydro-galactose bridges ${ }^{33}$.

Figure 4 shows the FTIR spectra of chitosan and agar blend films containing various agar proportions. A summary of characteristic bands of chitosan and agar blend films is also presented in Table 1. As can be seen, the increase in the agar content in the blend films caused a decrease in the intensity of the band arising from the $\mathrm{NH}$ bending (amide II) at $1560 \mathrm{~cm}^{-1}$ of chitosan. This was coupled with a similar decrease in the absorbance band at $1411 \mathrm{~cm}^{-1}$ and an increase in the band absorbance at $1380 \mathrm{~cm}^{-1}$. Furthermore, the spectra of blend films show the disappearance of the intensive band at $1033 \mathrm{~cm}^{-1}$ that was obviously observed in the pure chitosan film and chitosan/agar blend containing agar content of $10 \%$. This is due to the fact that mixing two or more polymers leads to changes in characteristic peaks occurrence as a reflection of the physical and chemical interactions ${ }^{34,35}$. These observations indicate the existence of good miscibility between chitosan and agar, which is most likely caused by the formation of intermolecular hydrogen bonds between the amino and hydroxyl groups in chitosan and the hydroxyl groups in agar. 


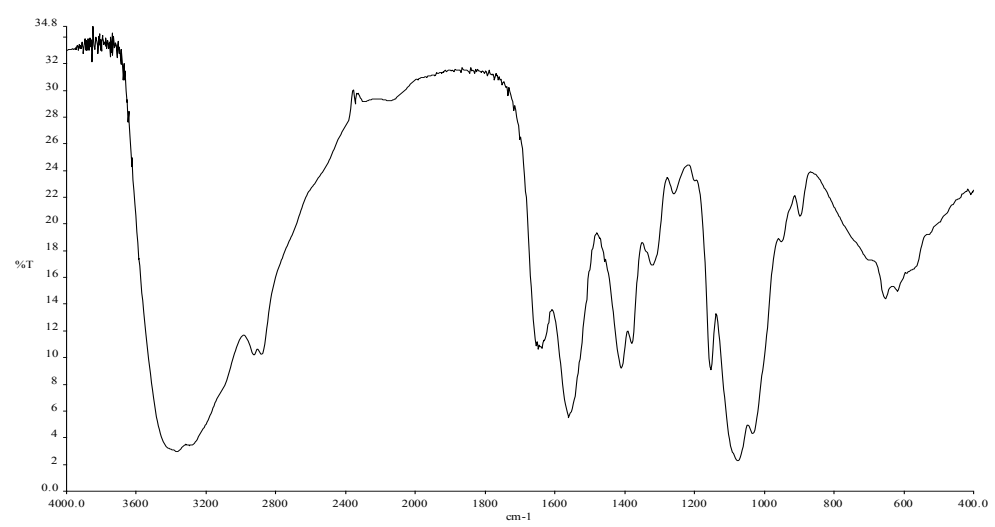

Figure 2: Typical FTIR spectrum of pure chitosan film.

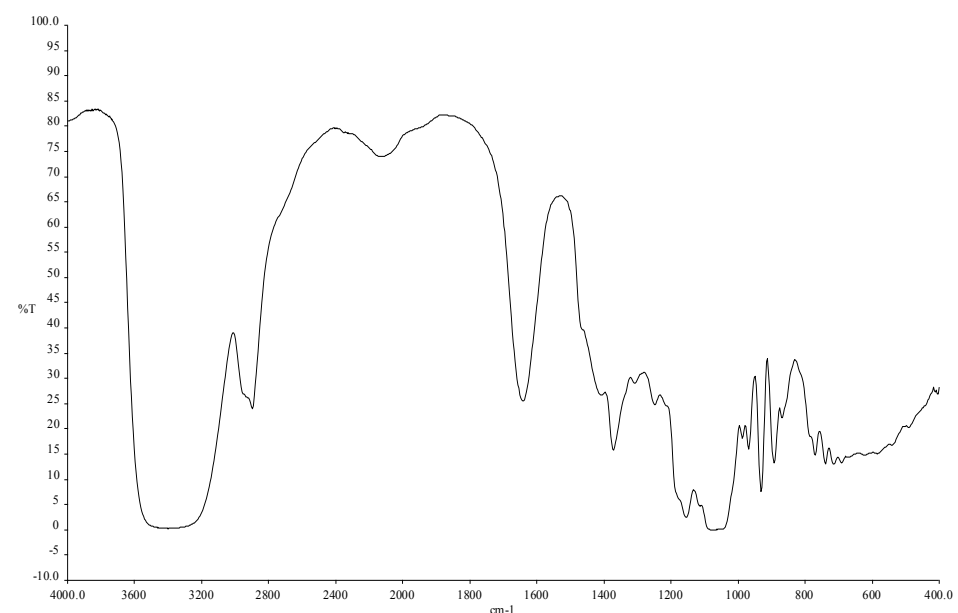

Figure 3: Typical FTIR spectrum of pure agar film.

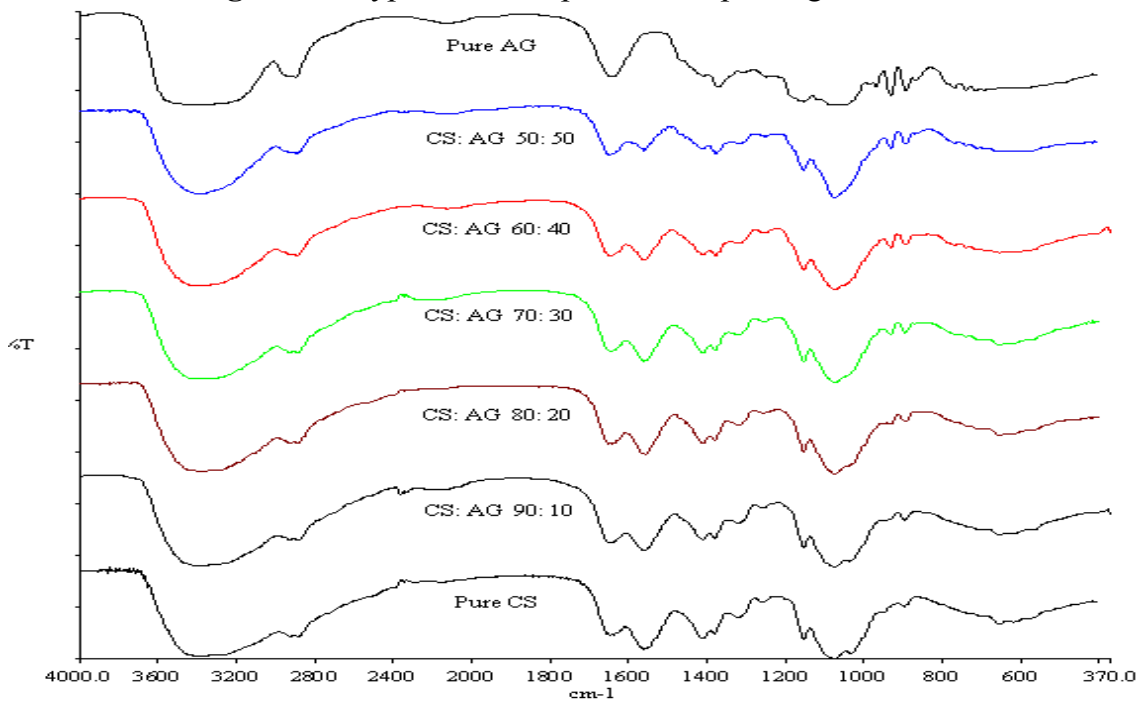

Figure 4: Typical FTIR spectra of chitosan/agar blend films having various proportions. 
Table 1. FTIR characteristic bands of chitosan/agar blend films at various proportions.

\begin{tabular}{ccccccc}
\hline $\begin{array}{c}\text { Chitosan/agar } \\
(\%)\end{array}$ & OH & $\begin{array}{c}\mathrm{C}=\mathrm{O} \\
\text { (amide I })\end{array}$ & $\begin{array}{c}\mathrm{NH} \\
(\text { amide II })\end{array}$ & $\begin{array}{c}\mathrm{CH} \\
\text { (amide II) }\end{array}$ & C-C & $\mathrm{C}-\mathrm{O}$ \\
\hline $100 / 0$ & 3368 & 1648 & 1561 & 1411 & 1380 & 1033 \\
\hline $90 / 10$ & 3368 & 1647 & 1559 & 1412 & 1379 & 1035 \\
\hline $80 / 20$ & 3371 & 1651 & 1558 & 1411 & 1379 & - \\
\hline $70 / 30$ & 3368 & 1646 & 1559 & 1411 & 1379 & - \\
\hline $60 / 40$ & 3371 & 1647 & 1560 & 1412 & 1378 & - \\
\hline $50 / 50$ & 3379 & 1647 & 1559 & 1417 & 1376 & - \\
\hline $0 / 100$ & 3400 & 1643 & - & 1409 & 1373 & - \\
\hline
\end{tabular}

\section{Surface analysis}

Figure 5 shows the SEM micrographs of surfaces of chitosan/agar blend films containing different proportions of agar together with the corresponding ones of pure chitosan and agar films. As can be seen, chitosan film shows smooth and homogeneous surface with some straps unlike that of pure agar which exhibits a rougher surface. The surfaces of the blend films of chitosan and agar seem to have no interface layer and more homogeneous than that of pure chitosan and agar films. This confirms that chitosan and agar are highly compatible. The formation of homogeneous blends of chitosan and agar was mostly caused by the interactions of hydrogen bonds between the functional groups of the blend component $(-\mathrm{OH}$ and $-\mathrm{NH}_{2}$ groups in chitosan and $-\mathrm{OH}$ groups in agar).

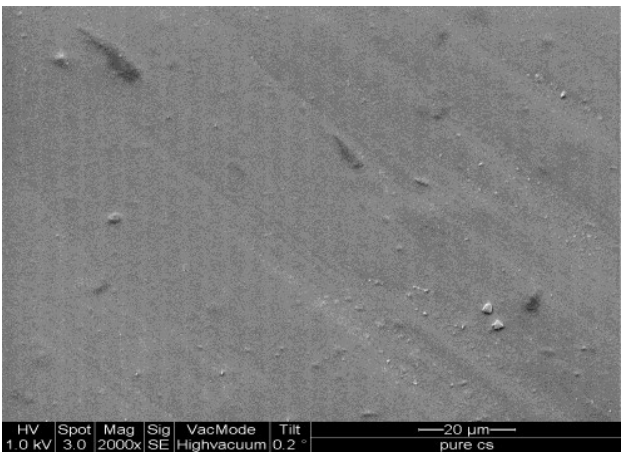

(a)

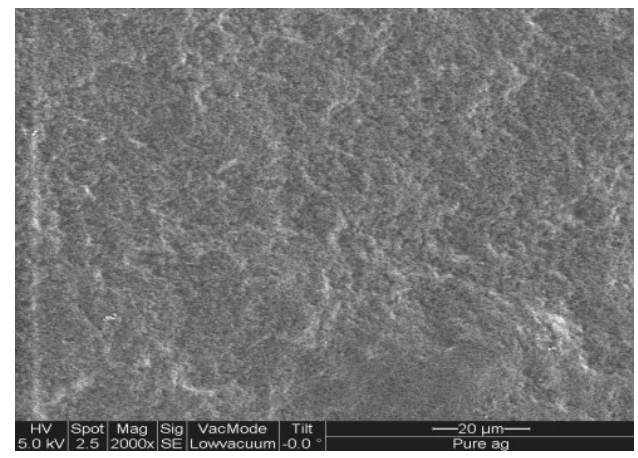

(b) 


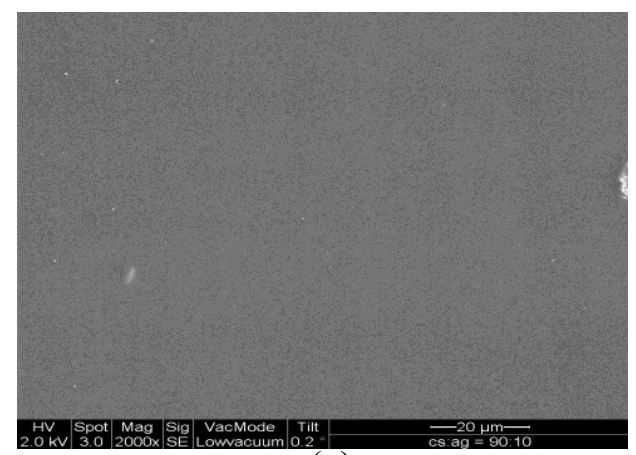

(c)

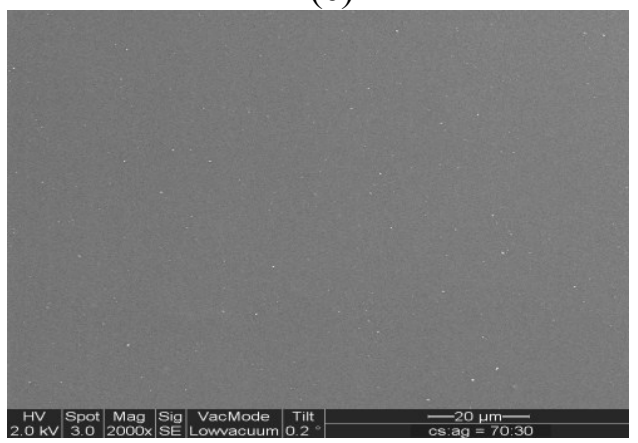

(e)

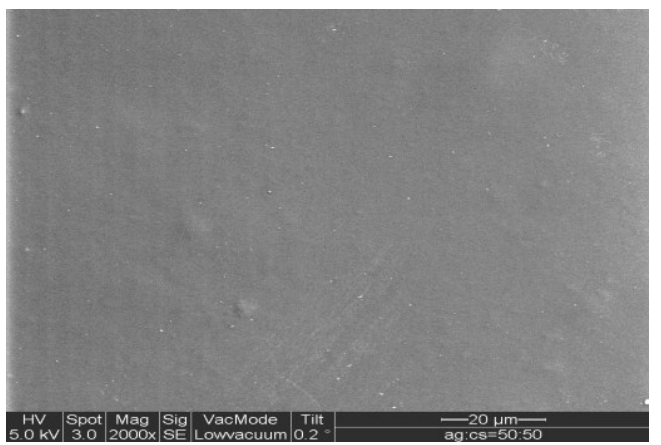

(g)

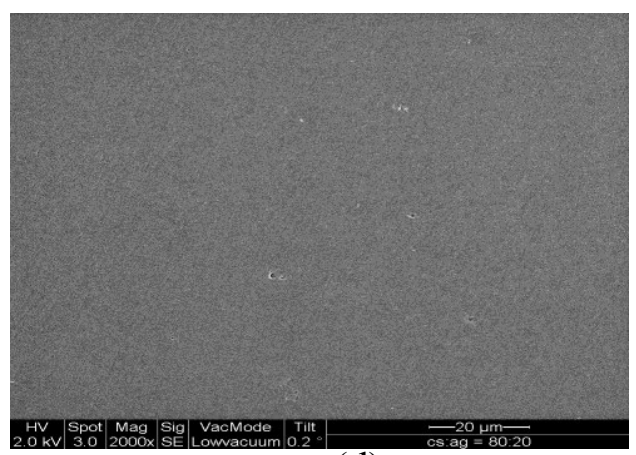

(d)

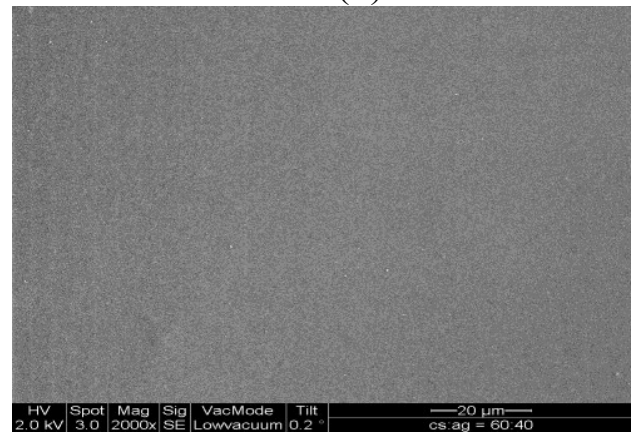

(f)

Figure 5: SEM micrographs of chitosan/agar blend films (a) 100/0, (b) 0/100, c) 90/10, (d) 80/20, (e) 70/30, (f) 60/40 and (g) 50/50.

\section{Effect of the agar content on the thickness of the blend}

The variation of the thickness of pure chitosan film and its blends with agar prepared using the same amount of solution $(10 \mathrm{~mL})$ is shown in Figure 6 . The thickness increased from 0.012 to $0.016 \mathrm{~mm}$ when agar concentration was raised from 10 to $40 \%$ beyond which the increase in agar content does not bring any significant changes to the thickness of the blend film. The increase in the thickness with increasing agar content is most likely due to the combined hydrophilic nature of the agar associated with water molecules involved in hydrogen bonding with that of chitosan. Such water molecules remain bound to the films even after standard drying procedure. The absence of significant changes in the thickness at agar concentration beyond $40 \%$ could be due to a compensating expansion that might took place in the other two dimensions of the films i.e. the width and length or/and the existence of moisture equilibrium relationships at film-air interfaces. 


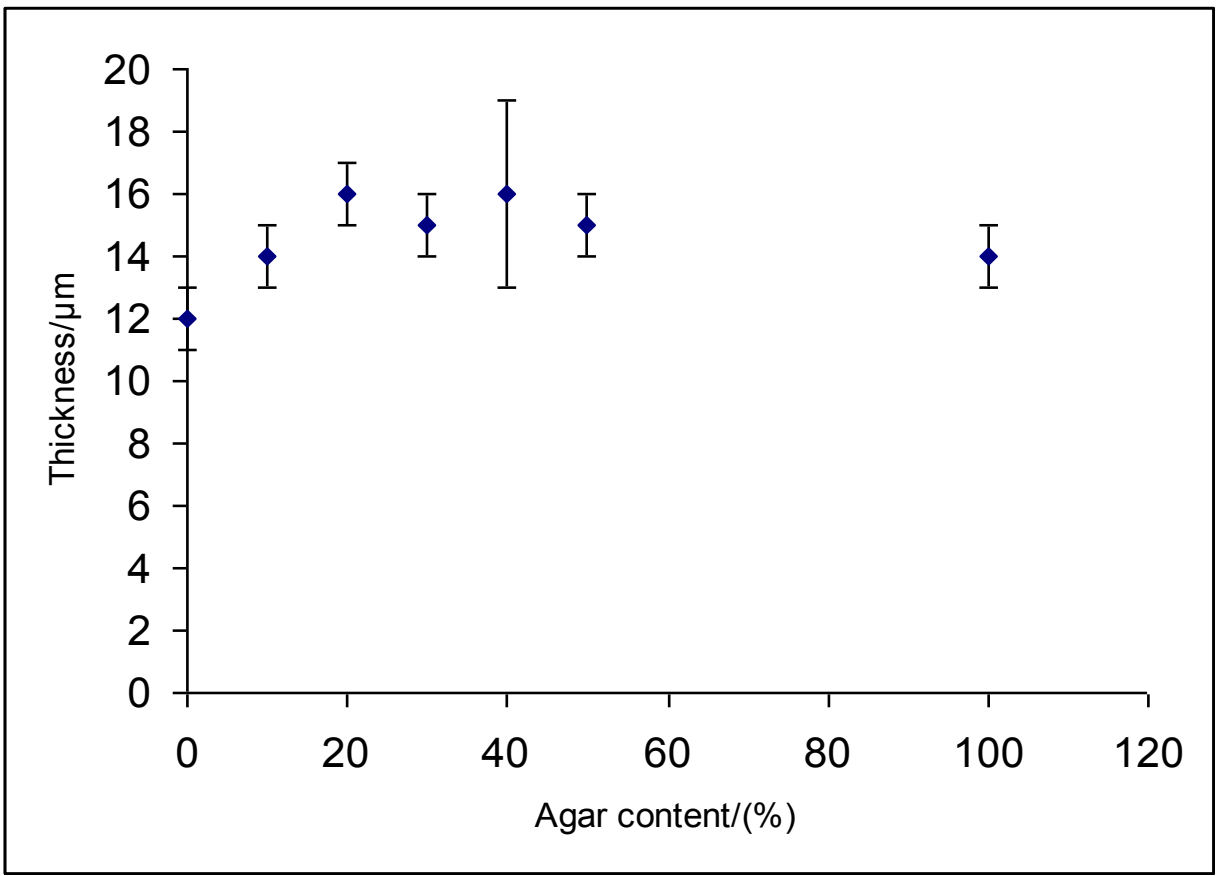

Figure 6: The thickness of the chitosan/agar blend film as a function of agar content.

\section{Conclusions}

Blends of chitosan and agar in film forms have been successfully prepared at various proportions in the range of 90/10-50/50 (v:v). The obtained blended films possess hydrogelic nature and can be characterized by high miscibility between chitosan and agar as confirmed by the results of FTIR and FESEM. It was also found that the blended films displayed homogenous and smooth surface properties compared to the individual pure components.

\section{Acknowledgment}

The authors would like to acknowledge the financial support by University of Malaya under research grant \# PS188/2008A.

\section{References}

1. Wood D, World Patent Information, 2010, 23, 339.

2. Neto C G T, Giacometti J A, Job A E, Ferreira F C, Fonseca J L C and Pereira M R, Carbohydr. Polym., 2005, 62, 97.

3. Molinaro G, Leroux J C, Damas J and Adam A, Biomaterials. 2002, 23, 2717.

4. Suh J K, Matthew H W, Biomaterials. 2000, 21, 2589.

5. Yang M Y, Su W Y, Leu T L and Yang M C, J. Membr. Sci., 2004, 236, 39.

6. Cho Y W, Cho Y N, Chung S H and Ko W, Biomaterials. 1999, 20, 2139.

7. Pillai O and Panchagnula R, Curr. Opin. Chem. Biol., 2001, 5, 447. 
8. Khor E and Lim L Y, Biomater., 2003, 24, 2339.

9. Yuan S and Wei T, J. Bioact. Compat. Polym., 2004, 19, 467.

10. Crini G, Bioresour. Technol., 2006, 97, 1061.

11. Hosokawa J, Nishiyama M, Yoshihara K and Kubo T, Ind. Eng. Chem. Res., 1990, 29, 800.

12. Hasegawa M, Isogai A, Onabe F, Usuda M and Atalla R H, J. Appl. Polym. Sci., 1992, 45, 1873.

13. Xu Y X, Kim K M, Hanna M A and Nag D, Ind. Crop. Prod., 2005, 21, 185.

14. Cheng M, Deng J, Yang F, Gong Y, Zhao N and Zhang X, Biomaterials. 2003, 24, 2871.

15. Ye Y, Dan W, Zeng R, Lin H, Dan N, Guan L and Mi Z, Eur. Polym. J., 2007, 43, 2066.

16. Araki C, Arai K and Hirase S, Bull. Chem. Soc. Japan. 1967, 40, 959.

17. Stephen A M, Phillips G O and Williams P A, Food polysaccharides and their applications; Marcel Dekker Inc: New York, 1995, 187.

18. Glicksman M, Gelling hydrocolloids in product applications, in: J. M. V. Blanshard, J. R. Mitchell (Eds), Polysaccharides in foods, Butterworths, London, 1979, 185.

19. Armisen R and Galatas F, Agar, in Philips G O and Williams P A (Eds.), Handbook of hydrocolloids; CRC Press: New York, 2000, 21.

20. Armisen R, J. Appl. Phycol., 1995, 7, 231.

21. Freile-Pelegrín Y, Madera-Santana T, Robledo D, Veleva L, Quintana P and Azamar J A, Polym. Degrad. Stab., 2007, 92, 244.

22. Rosiak J, Ulanski P and Rzeznicki A, Nucl. Instrum. Methods. Phys. Res., Sect B., 1995, 105, 335.

23. Muzzarelli R A A A and Rochetti R, Carbohydr. Polym., 1985, 5, 461.

24. Ladet S, David L and Domard A, Nature. 2008, 452, 76.

25. Notin L, Viton C, David L, Alcouffe P, Rochas C and Domard A, Acta. Biomater., 2006, 2, 387.

26. Houbin Li, Yumin Du, Xiaojun Wu and Huaiyu Zhan, Eng. Aspects. 2004, 242, 1.

27. Pawlak A and Mucha M, Thermochimica Acta. 2003, 396, 153.

28. Nunthanid J, Puttipipatkhachorn S, Yamamoto K and Peck G E, Drug Dev. Ind. Pharm., 2001, 27, 143.

29. Ritthidej G C, Phaechamud T and Koizumi T, Int. J. Pharm., 2002, 232, 11.

30. Tako M, Higa M, Medoruma K and Nakasone Y, Bot. Mar., 1999, 42, 513.

31. Armise'n R and Galatas F, FAO Fish Tech. Papers. 1987, 288, 1.

32. Cristiaen D and Bodard M, Bot. Mar., 1983, 26, 425.

33. Chirapart A, Ohno M, Ukeda H, Sawamura M and Kusunose H, Appl. Phycol., 1995, $7,359$.

34. Guan Y L, Liu X F, Zhang Y P and Yao K D, J. Appl. Polym. Sci., 1998, 67, 1965.

35. Yin Y J, Yao K D and Cheng G X, J. B. Ma, Polym. Int., 1999, 48, 429. 


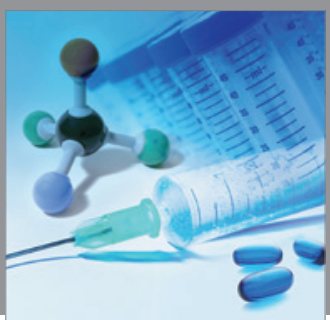

International Journal of

Medicinal Chemistry

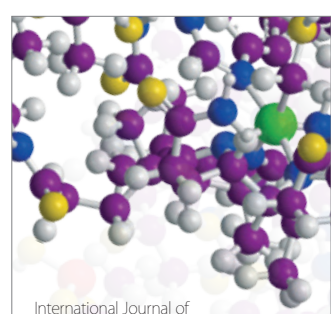

Carbohydrate Chemistry

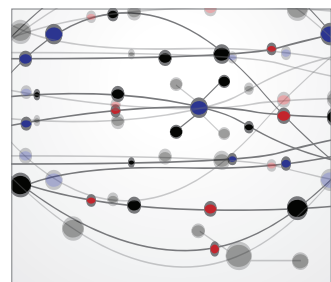

The Scientific World Journal
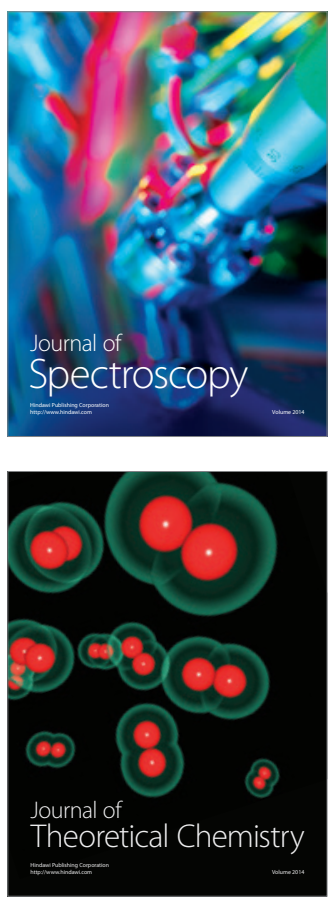
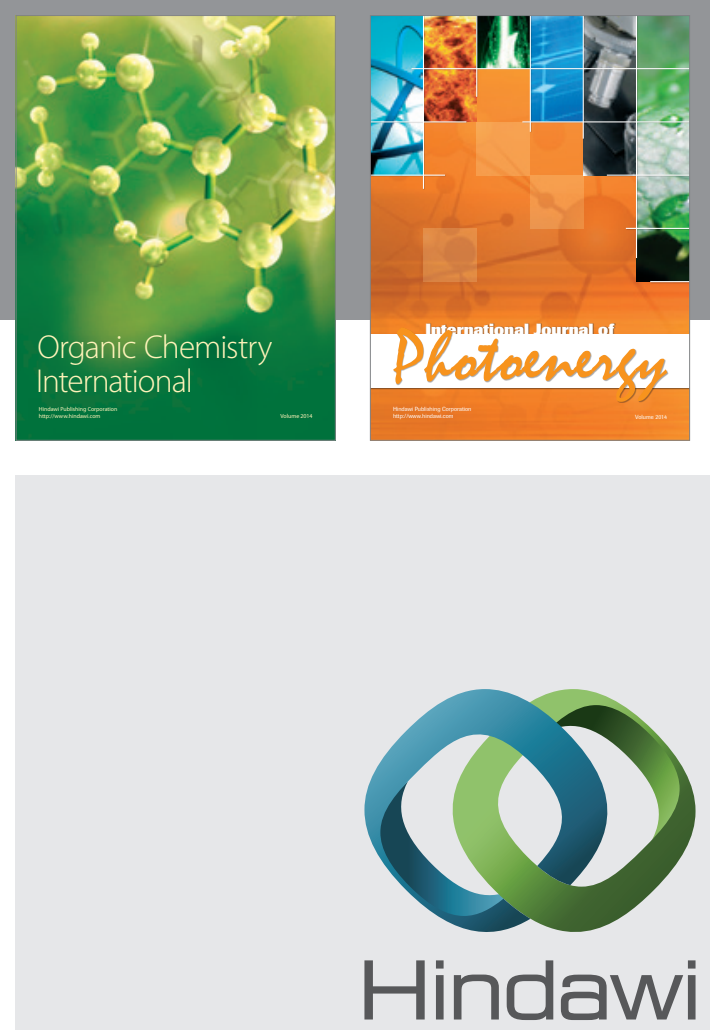

Submit your manuscripts at

http://www.hindawi.com
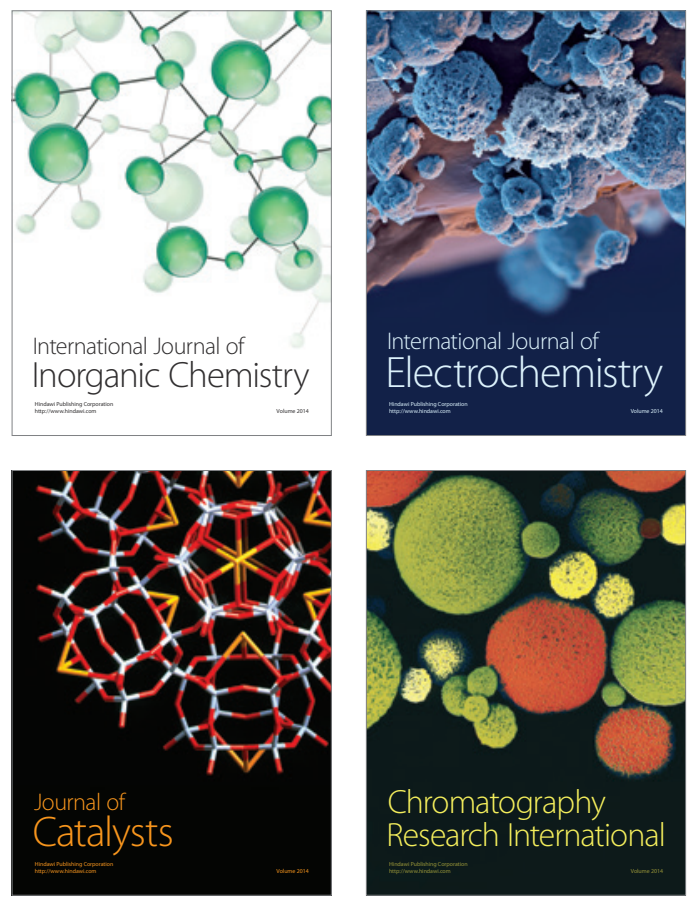
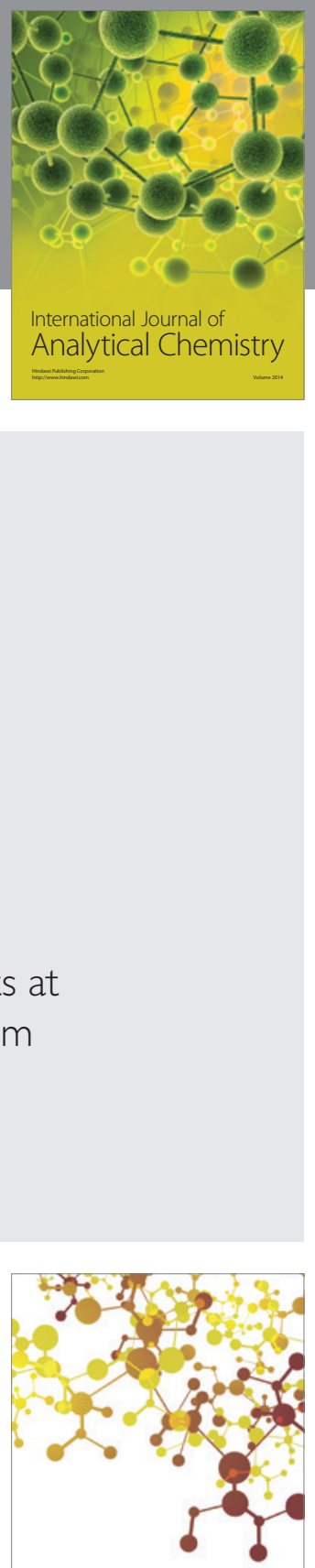

Journal of

Applied Chemistry
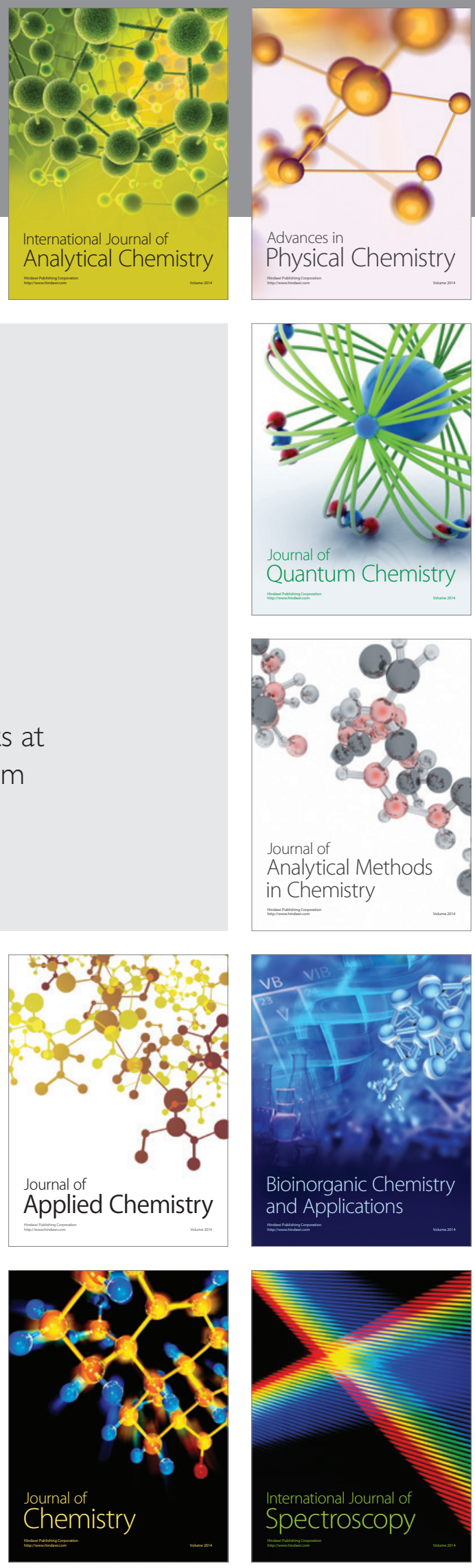